\title{
Erratum to: Review: Mechanical Impedance and Its Relations to Motor Control, Limb Dynamics, and Motion Biomechanics
}

\author{
Joseph Mizrahi ${ }^{1}$
}

Published online: 21 August 2015

(C) Taiwanese Society of Biomedical Engineering 2015

\section{Erratum to: J. Med. Biol. Eng. (2015) 35:1-20 DOI 10.1007/s40846-015-0016-9}

In the original publication, the article title was appeared incorrectly as "Mechanical Impedance and Its Relations to Motor Control, Limb Dynamics, and Motion Biomechanics".
The correct title should read as "Review: Mechanical Impedance and Its Relations to Motor Control, Limb Dynamics, and Motion Biomechanics".

The online version of the original article can be found under doi:10. 1007/s40846-015-0016-9.

Joseph Mizrahi

jm@bm.technion.ac.il

1 Department of Biomedical Engineering, Technion - Israel, Institute of Technology, 32000 Haifa, Israel 